\title{
Description of three Rhacophorus tadpoles (Lissamphibia: Anura: Rhacophoridae) from Sarawak, Malaysia (Borneo)
}

\author{
ALEXANDER HAAS ${ }^{1,5}$, STEFAN T. HERTWIG ${ }^{2}$, WENKE KRINGS ${ }^{1}$, ENZO BRASKAMP ${ }^{1}$, J. MAXIMILIAN \\ DEHLING $^{3}$, PUI YONG MIN ${ }^{4}$, ANDRÉ JANKOWSKI $^{1}$, MANUEL SCHWEIZER $^{2} \&$ INDRANEIL DAS $^{4}$ \\ ${ }^{1}$ Zoologisches Museum Hamburg, Martin-Luther-King-Platz 3, 20146 Hamburg, Germany \\ ${ }^{2}$ Naturhistorisches Museum der Burgergemeinde Bern, Bernastrasse 15, CH-3005 Bern, Switzerland \\ ${ }^{3}$ Institut für Integrierte Naturwissenschaften, Abteilung Biologie, Universität Koblenz-Landau, Universitätsstraße 1, 56070 Koblenz, \\ Germany \\ ${ }^{4}$ Institute of Biodiversity and Environmental Conservation, Universiti Malaysia Sarawak, 94300 Kota Samarahan, Sarawak, \\ Malaysia; idas@ibec.unimas.my \\ ${ }^{5}$ Corresponding author: E-mail: alexander.haas@uni-hamburg.de
}

\begin{abstract}
This communication reports the discovery of the hitherto unknown larval forms of Rhacophorus rufipes and R. penanorum, and re-describes the tadpole of $R$. dulitensis. Tadpoles of all three species were discovered at Gunung Mulu National Park, Sarawak (Borneo), Malaysia. The identity of the larvae was determined by DNA barcoding techniques using partial 16S rRNA mitochondrial gene sequences. Larval DNA sequences matched those of syntopic adults of respective species. Detailed descriptions of external morphology and colouration in life are provided along with ecological notes. The tadpole of $R$. rufipes and $R$. dulitensis can be classified as generalized, benthic-nectonic type, whereas tadpoles of $R$. penanorum show adaptations typical for a lotic, rheophilous lifestyle.
\end{abstract}

Key words: Rhacophorus rufipes, $R$. penanorum, R. dulitensis, tadpole description, larval morphology, oral disc, rheophilous tadpole, DNA barcoding

\section{Introduction}

The identification of anuran amphibian larval stages is essential for many purposes and research objectives, such as regional surveys, habitat inventories, studies on resource use, interspecific competition studies, and for conservation. For rapid assessments of study sites, searching for, and identifying larvae in the field is necessary to optimize amphibian species counts. This is particularly true in structurally complex and species rich tropical habitats. A large number of frogs still lack detailed descriptions of their larval forms, although there has been a recent increase in efforts in tadpole surveys and tadpole fauna inventories (for example, Anstis 2002; Chou \& Lin 1997; Gawor et al. 2009; Leong \& Chou 1999; Das \& Haas 2011; Haas \& Das 2011). The Sundaland is a biodiversity hotspot of global importance and the true number of frog species in the region remain unknown, and is probably underestimated (Inger 1999). The general lack of reliable information about larval forms is not expected to change in the near future as many new species of frogs continue to be discovered (AmphibiaWeb 2010) and because the majority of new species descriptions still focuses on the adult and very often neglect larval forms.

The tadpole fauna of the East Malaysian states of Sabah and Sarawak has been investigated since the mid1960s in a series of publications by Robert F. Inger and collaborators (Inger 1966; Inger 1983; Inger 1985; Inger et al. 2006). Recently, Das \& Haas (2005) and Haas \& Das (2011) gave an overview on the literature that provides data on larval identities of Bornean amphibians. Haas \& Das (2011) identified 32\% of all East Malaysian (Borneo) anuran species to have unknown larval forms. Even where descriptions are available for tadpoles, these are often incomplete (such as lacking images) or only in an abbreviated form. Often differential diagnostics or identification keys are not provided, making unambiguous identification of larvae in the lab or in the field challenging. 